\title{
Proliferative instability and experimental carcinogenesis at colonic anastomoses
}

\author{
R ROE, B FERMOR, AND R C N WILLIAMSON \\ From the University Department of Surgery, Bristol Royal Infirmary, Bristol
}

SUMmARY The possibility that proliferative instability around a healing anastomosis promotes carcinogenesis was tested in 234 male Sprague-Dawley rats. Animals received the first of five weekly injections of azoxymethane (total dose $50 \mathrm{mg} / \mathrm{kg}$ ) either immediately after transection of the descending colon or at 2, 4, 8, and 12 weeks later; controls received handling of the bowel alone. Crypt cell proliferation was assessed by autoradiography following ${ }^{3} \mathrm{HTdR}$ injection. An overall increase in tumour yields in all transection groups was due solely to the frequent presence of anastomotic tumours. Changes in crypt morphometry and labelling index were most marked in crypt positions 1-10 away from the anastomosis. Crypts at this site increased in height at 2, 4, and 8 weeks $(\mathrm{p}<0.001)$ but returned to normal values by 12 weeks. Likewise, labelling index was increased at 2,4 , and 8 weeks $(p<0.001)$ and remained higher at 12 weeks $(p<0.05)$. Increased crypt cell proliferation in the immediate vicinity of an apparently 'healed' colonic anastomosis may explain its persisting susceptibility to carcinogenesis.

Recurrence of colorectal carcinoma at the site of anastomosis is a common clinical problem, although its reported incidence varies widely between 10 $48 \% .{ }^{1-4}$ Some early recurrences represent inadequate excision of the primary tumour or adjacent lymphatics, and others could follow the implantation of viable carcinoma cells on the suture line. ${ }^{5}$ For 'recurrent' cancer arising two years or more after primary resection, however, metachronous carcinogenesis at the anastomosis seems a more likely explanation. Multiple colorectal carcinomas are known to occur in at least $3 \%$ of patients, ${ }^{2}$ and adenomas coexist with carcinoma in some $22 \%$ of cases. $^{6}$

Previous work from this laboratory and elsewhere has shown a high incidence of tumours in the immediate vicinity of a large bowel anastomosis in rats receiving azoxymethane or dimethylhydrazine. ${ }^{78}$ As this phenomenon occurs whether carcinogen treatment immediately precedes or follows transection and resection of the bowel, ${ }^{7}$ proliferative insta-

Address for correspondence: Professor R C N Williamson, University Dept of Surgery, Bristol Royal Infirmary, Bristol BS2 $8 \mathrm{HW}$.

Received for publication 21 November, 1986 bility of the epithelium around the anastomosis may play an important role.

The present study was designed to investigate the relationship between the proliferative status of the mucosa and the susceptibility of an anastomosis to increased tumour development. Our data suggest that even healed anastomoses are preferential sites for colorectal carcinogenesis.

\section{Methods}

\section{EXPERIMENTAL DESIGN}

Young, male Sprague-Dawley rats $(\mathrm{N}=234)$ weighing approximately $200 \mathrm{~g}$ were allocated to one of five experimental groups (Fig. 1). Each group contained 48 rats, except that group 5 contained 42 rats only. Half the rats within groups 1-4 received transection of the mid descending colon and half received sham transection - that is, handling of the bowel alone - on weeks $0,4,8$, and 10 of the experiment. On week 12 , 18 rats from group 5 received transection and 18 received sham transection. The remaining six unoperated rats were included in the crypt cell proliferation analysis. Laparotomy was done under light ether anaesthesia. Continuous silk $6 / 0$ sutures 


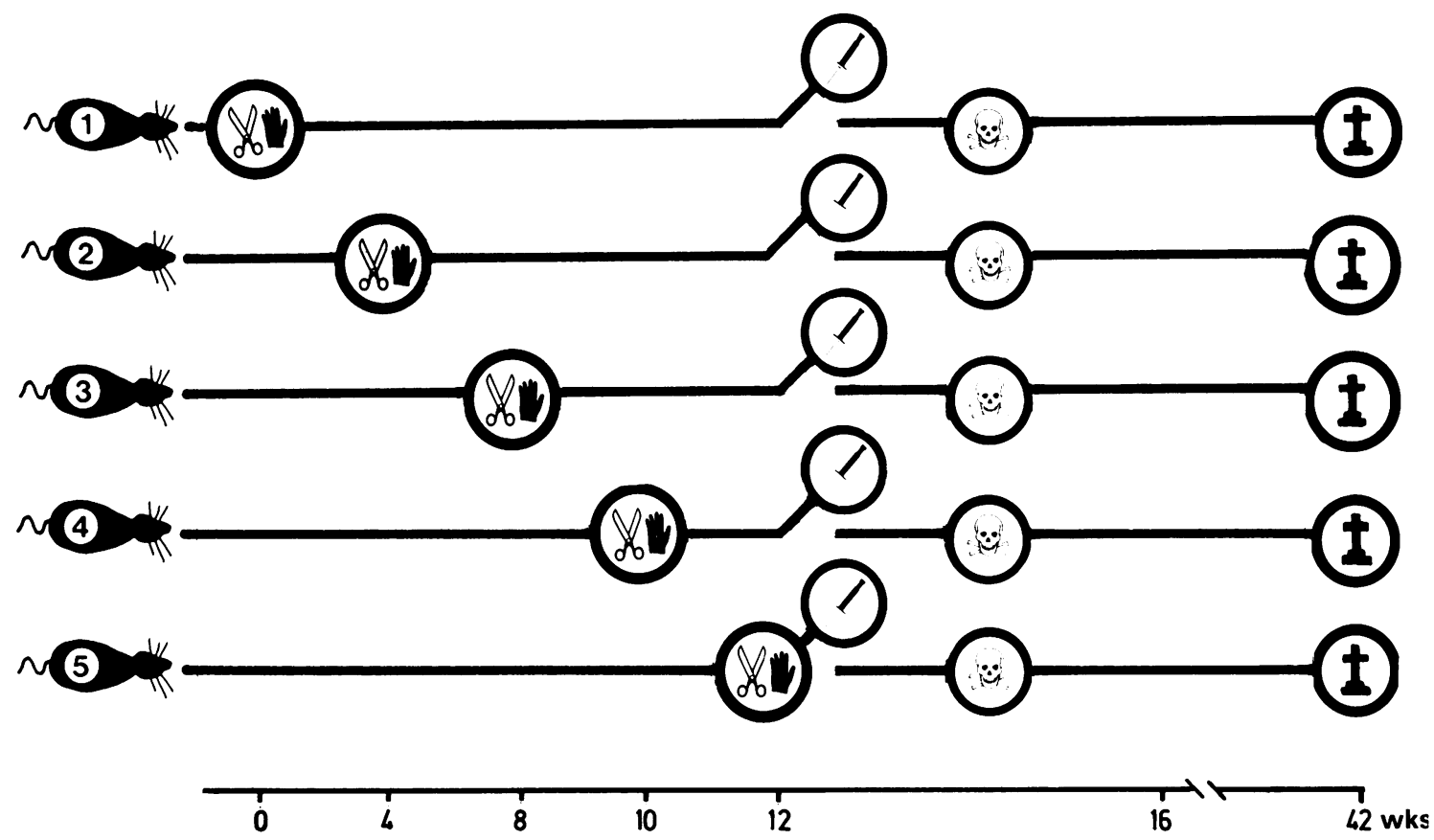

Fig. 1 Experimental design.

were used for all colonic anastomoses, and a marker stitch was placed on the serosal aspect of the bowel at this point.

At $12,8,4,2$ or 0 weeks postoperatively groups of animals received the first of five weekly sc injections of azoxymethane (Ash-Stevens Inc, Detroit, Michigan, USA) at a dose of $10 \mathrm{mg} / \mathrm{kg}$. Thus in group 1,12 weeks elapsed between creation of the anastomosis and first exposure to carcinogen, whereas in group 5 azoxymethane was first administered at the end of the operation.

Rats were weighed weekly throughout the experiment and were killed 30 weeks after the first injection of carcinogen. Premature evidence of tumour development - for example, progressive weight loss or rectal bleeding, led to earlier death in five cases. All rats received a full necropsy, in which the entire intestinal tract was flushed with ice cold saline and scrutinised for macroscopic tumours. All possible tumours and sites of metastasis were fixed in $10 \%$ formol saline for subsequent histological examination.

CRYPT MORPHOMETRY AND LABELLING INDICES At time periods $2,4,8$, and 12 weeks after transection or sham transection, six rats were selected from each group at the same time of day. In addition six unoperated rats were selected from group 5. In each case five rats received a single ip injection of tritiated thymidine, ${ }^{3} \mathrm{HTdR}$ (Radiochemical Centre, Amersham, England) at a dose of $0.5 \mathrm{mCi} / \mathrm{kg}$ body weight (specific activity $5 \mathrm{Ci} / \mathrm{mmol}$ ); one rat received an injection of saline. One hour later animals were killed. The colorectum was excised, flushed clean with ice cold saline and pinned mucosal side uppermost to a cork board before fixation in $10 \%$ formol saline. The site of the anastomosis was identified by the presence of the marker stitch.

Longitudinal slices $3 \mathrm{~mm}$ thick were cut directly through the anastomosis and including tissue up to $1 \mathrm{~cm}$ on either side of the anastomosis. Histological sections ( $3 \mu \mathrm{m}$ thick) were cut at several levels, and autoradiographs were subsequently prepared by the stripping film technique. ${ }^{9}$ Exposure was for three weeks, after which development slides were stained with Mayer's haematoxylin.

To determine whether any changes in morphometry or proliferative activity were local to the anastomosis or more widespread, crypts were examined at five points (A-E) on either side of the suture line at each time point of healing. Point A represented the 10 crypts closest to the anastomosis, point $B$ crypt positions $11-20$, point $C$ crypt positions 21-30, point $\mathrm{D}$ crypt positions $31-40$, and point $\mathrm{E}$ crypt positions $41-50$ away from the anastomosis. It was difficult to obtain perfect axially sectioned crypts close to the anastomosis, and the maximum number of suitable crypts at each point was 12 for each rat 

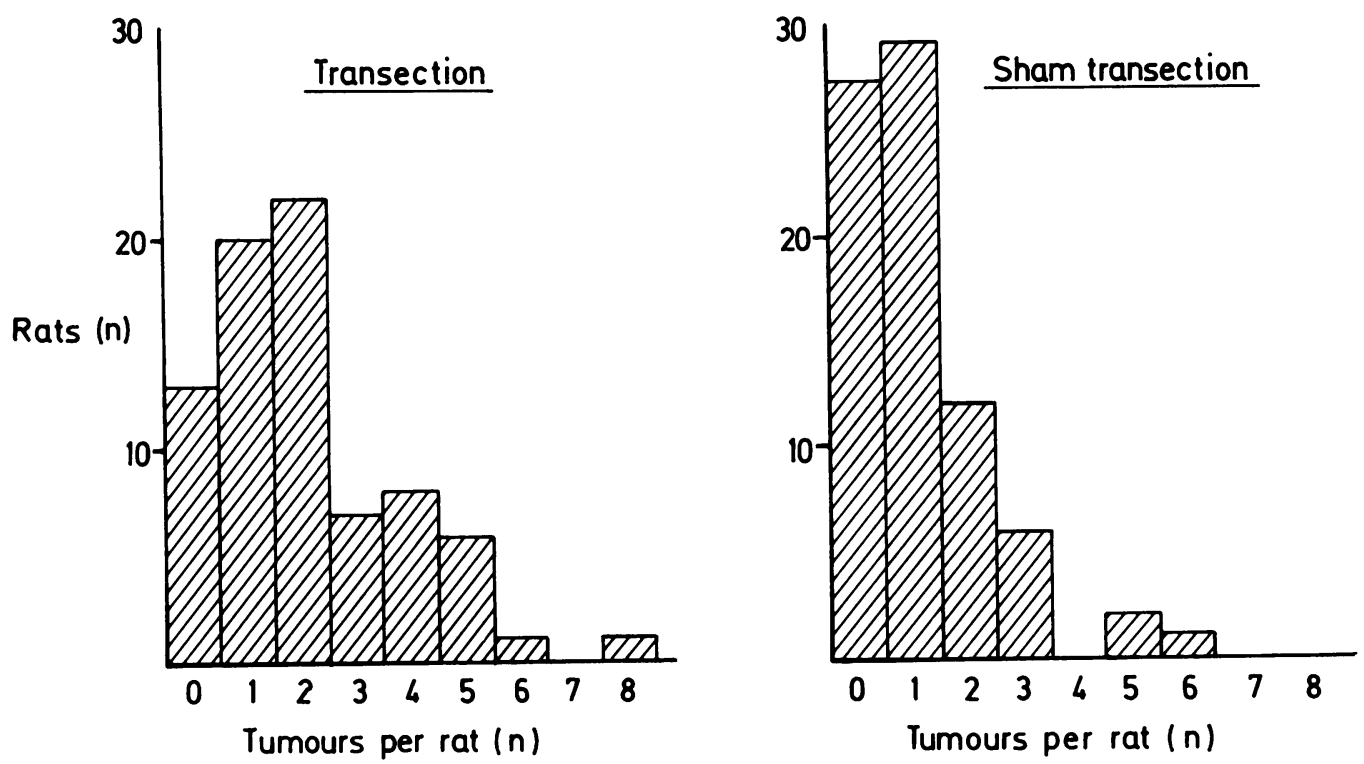

Fig. 2 Tumour incidence in rats receiving transection and sham transection.
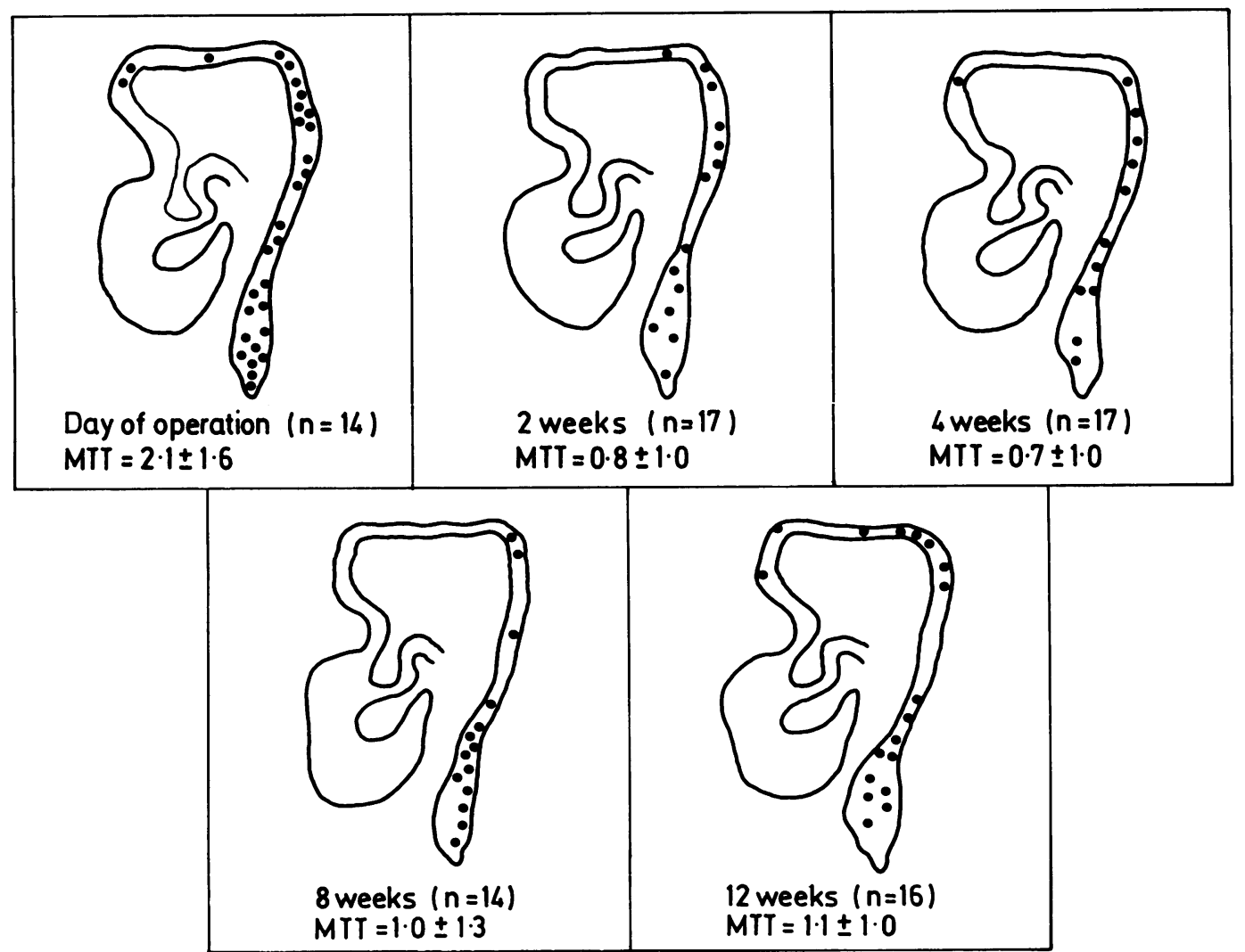

Fig. 3 Total tumour yields in rats receiving sham transection. $M T T=$ mean total tumour yield per rat $\pm S D$. 

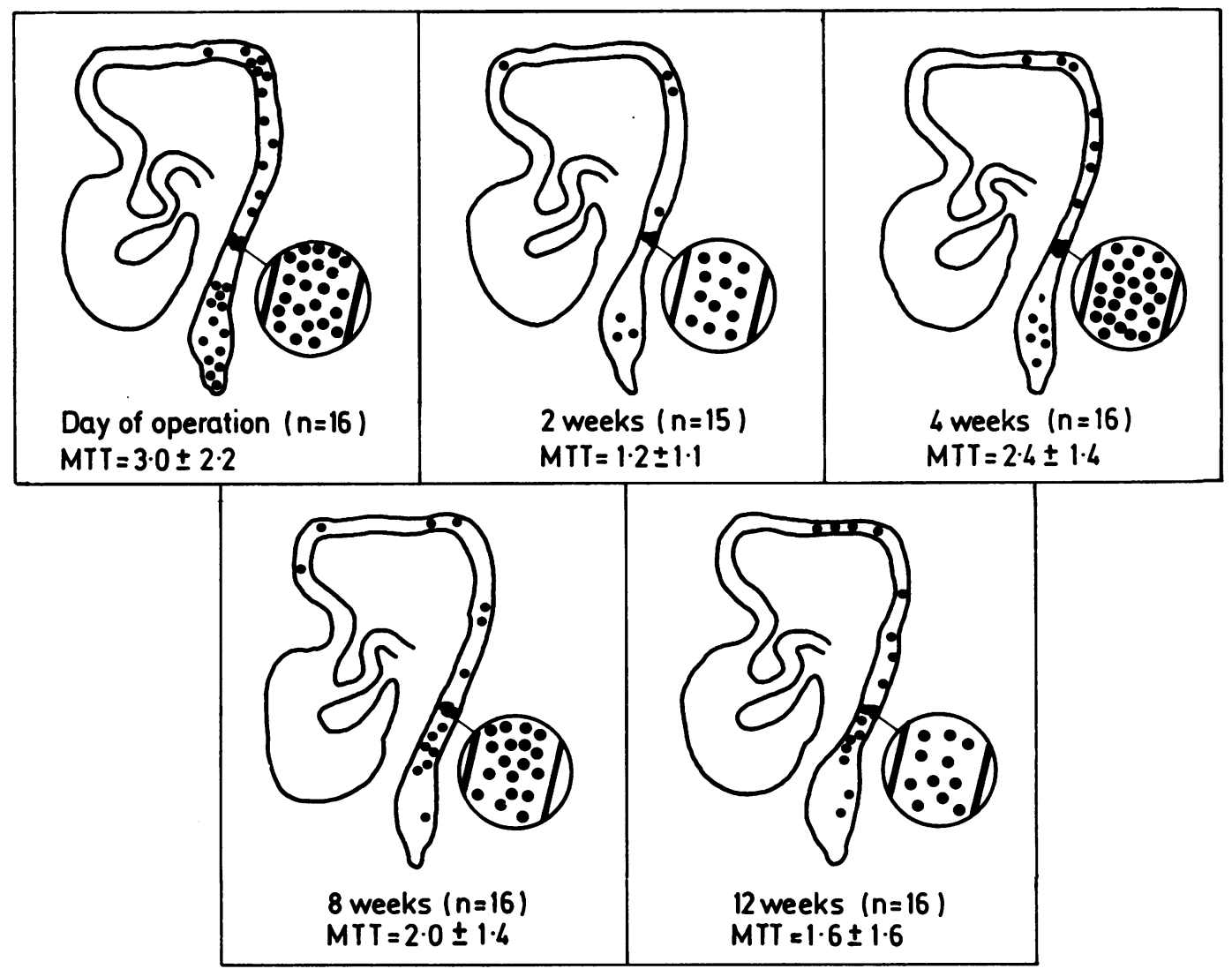

Fig. 4 Total tumour yields in rats receiving transection. $M T T=$ mean total tumour yield per rat $\pm S D$.

examined. The total number of cells in the left hand column of each crypt was recorded, together with the number of labelled epithelial cells. The criterion for a labelled nucleus was five or more autoradiographic grains located directly over it.

\section{STATISTICAL ANALYSIS}

Tumour data were analysed using a GENSTAT. statistical package to fit a generalised linear model with Poisson errors. Crypt morphometry and labelled nuclei data were analysed using a repeated measures analysis of variance.

\section{Results}

SURVIVA L

Eighteen animals died during the early weeks of mycoplasma pneumonia, including some from each group. None of them exhibited bowel tumours and they were excluded from analysis. Five rats dying of obstructing carcinomas before 30 weeks were included in the analysis of tumour data.
COLORECTAL TUMOUR YIELDS

Overall, $64 \%$ of rats with sham transection developed colonic tumours compared with $85 \%$ with transection (Fig. 2). While most rats with sham transection developed one colonic tumour only, those with transection developed at least two. As previously observed, ${ }^{7}$ most tumours arose on the left side of the colon irrespective of the type of operation (Figs 3 and 4). Among shams, tumour yields in rats receiving azoxymethane from the day of operation (mean 2.1 tumours per rat) were approximately twice those in rats in which carcinogen administration was delayed $(0 \cdot 7-1 \cdot 1)$.

In rats receiving transection of the lower left colon a substantial proportion of tumours was associated with the suture line at each time period: $23 / 48$ when azoxymethane was received on the day of operation, $12 / 18$ at two weeks, $25 / 38$ at 4 weeks, $18 / 32$ at eight weeks and 11/26 at 12 weeks. As seen in the shams, mean tumour yields were again higher when azoxymethane was started on the day of operation (mean 3.0 tumours per rat) than when carcinogen administration was delayed $(1 \cdot 2-2 \cdot 4)$. 


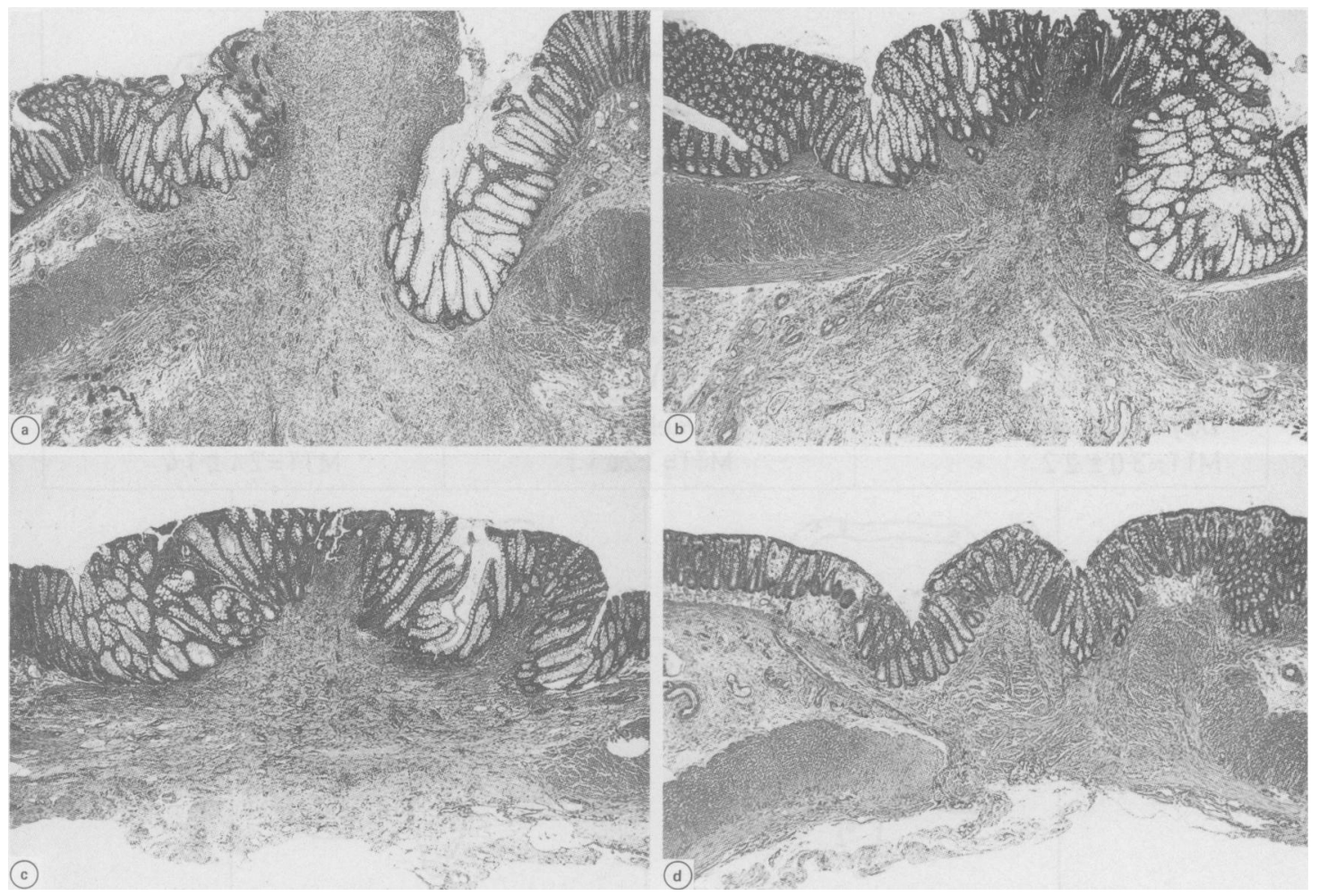

Fig. 5 Photomicrographs of a healing anastomosis at (a) 2 weeks (b) 4 weeks (c) 8 weeks and (d) 12 weeks after its creation.

In both shams and rats with transection approximately half the colonic tumours were adenomas and half were adenocarcinomas. Likewise, anastomotic tumours were equally distributed between benign and malignant neoplasms in each group. Four rats developed granulomas in response to the marker stitch placed on the serosal side of the colon.

\section{EFFECT OF HEALING ON ANASTOMOTIC TUMOUR} YIELDS

Histological sections taken through the anastomosis show that re-epithelialisation of colonic epithelium is complete at 12 weeks following transection of the bowel (Fig. 5).

To determine whether increased healing of the anastomosis influenced its susceptibility to carcinogenesis, the individual effects of transection and timing of carcinogen administration were analysed both for total colorectal tumours and for extra anastomotic tumours. A generalised linear model with Poisson errors was fitted to the tumour data (Fig. 6). Timing of carcinogen administration had a clear effect on both total and extra anastomotic tumour yields irrespective of transection, suggesting that susceptibility to azoxymethane decreased with age. Because colonic transection affected total tumour yields only and showed no interaction with time, the anastomosis was at greater risk of tumour development than intact mucosa elsewhere in the colon throughout the period of healing. At each time point after transection, the predicted increase in tumours arising at the anastomosis was constant at $77 \%$.

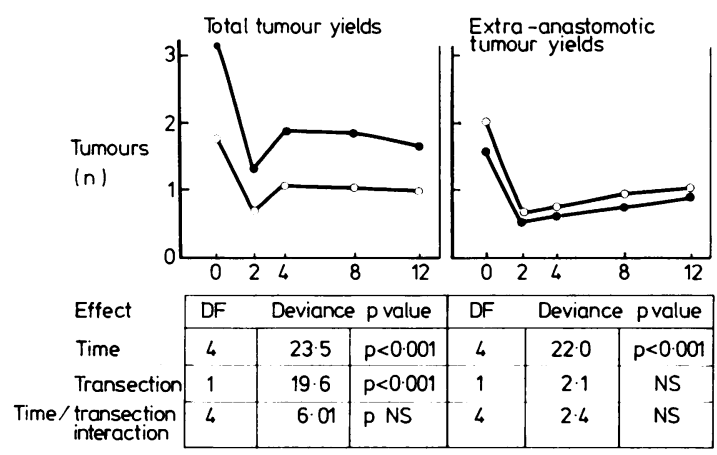

Fig. 6 Predicted tumour yields in rats receiving transection (-) and sham transection $(\mathrm{O}-\mathrm{O})$ using a generalised linear model with Poisson errors. 
ADAPTATION IN PERIANASTOMOTIC CRYPTS

Values for crypt height (Fig. 7) and labelling index (Fig. 8) at increasing distances away from the anastomosis are compared with control values obtained from young unoperated rats, as sham transection had no effect on either parameter at any time point (data not shown). The most striking differences were seen at crypt positions $1-10$ on either side of the anastomosis: crypt cellular height at this site increased by $38 \%$ at two weeks, $48 \%$ at four weeks, and $34 \%$ at eight weeks, returning to control values by 12 weeks. Labelling indices increased from control values of $10 \%$ to $24 \%$ at two weeks, $26 \%$ at four weeks, and $21 \%$ at eight weeks; although declining thereafter the labelling index at 12 weeks remained raised at $14 \%$.

\section{Discussion}

This study has shown that colonic anastomoses retain an increased susceptibility to carcinogenesis for up to three months after their creation. As cell proliferation in the immediate vicinity of the anastomosis is stimulated throughout this period, the results support our previous contention ${ }^{711 "}$ " that hyperplasia predisposes to neoplasia in the intestinal tract.

The large yield of tumours at the suture line is in agreement with the findings of previous studies with colonic transection, ${ }^{7}$ partial colectomy, ${ }^{7 \times}$ small bowel resection $^{810}$ and pancreaticobiliary diversion. "In all these studies carcinogen was administered either before the operation or immediately thereafter. It is therefore of interest that a 12 week anastomosis remains at greater risk of tumour development than mucosa elsewhere in the colon, despite a return to normal histological appearances.

By contrast, the general susceptibility to develop tumours throughout the colon was found to decrease with increasing time periods before carcinogen administration, independent of whether rats received transection or handling of the bowel. Perhaps postoperative hyperaemia delivers greater concentrations of the ultimate carcinogen to the large intestine; alternatively older rats are less susceptible to the carcinogen. ${ }^{12}$ Whatever the reason, the anastomosis is at an increased risk of carcinogenesis at each time point of healing.
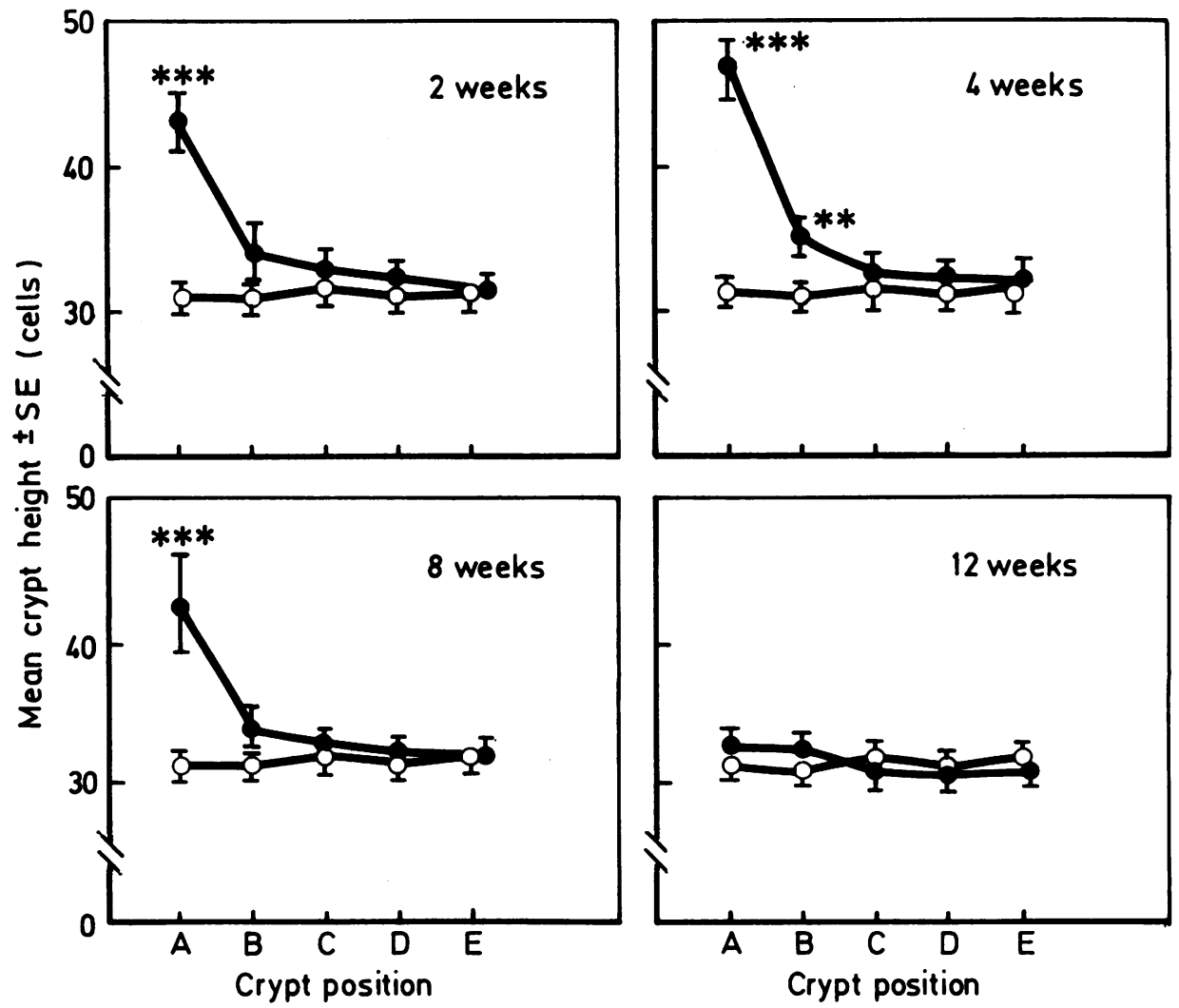

Fig. 7 Crypt height in unoperated control rats $\left(\mathrm{O}_{-} \mathrm{O}\right)$ and rats receiving transection $(\bigcirc-1)$ with time $\left({ }^{* * *} p<0 \cdot 001\right.$, ** $p<0.02)$. 

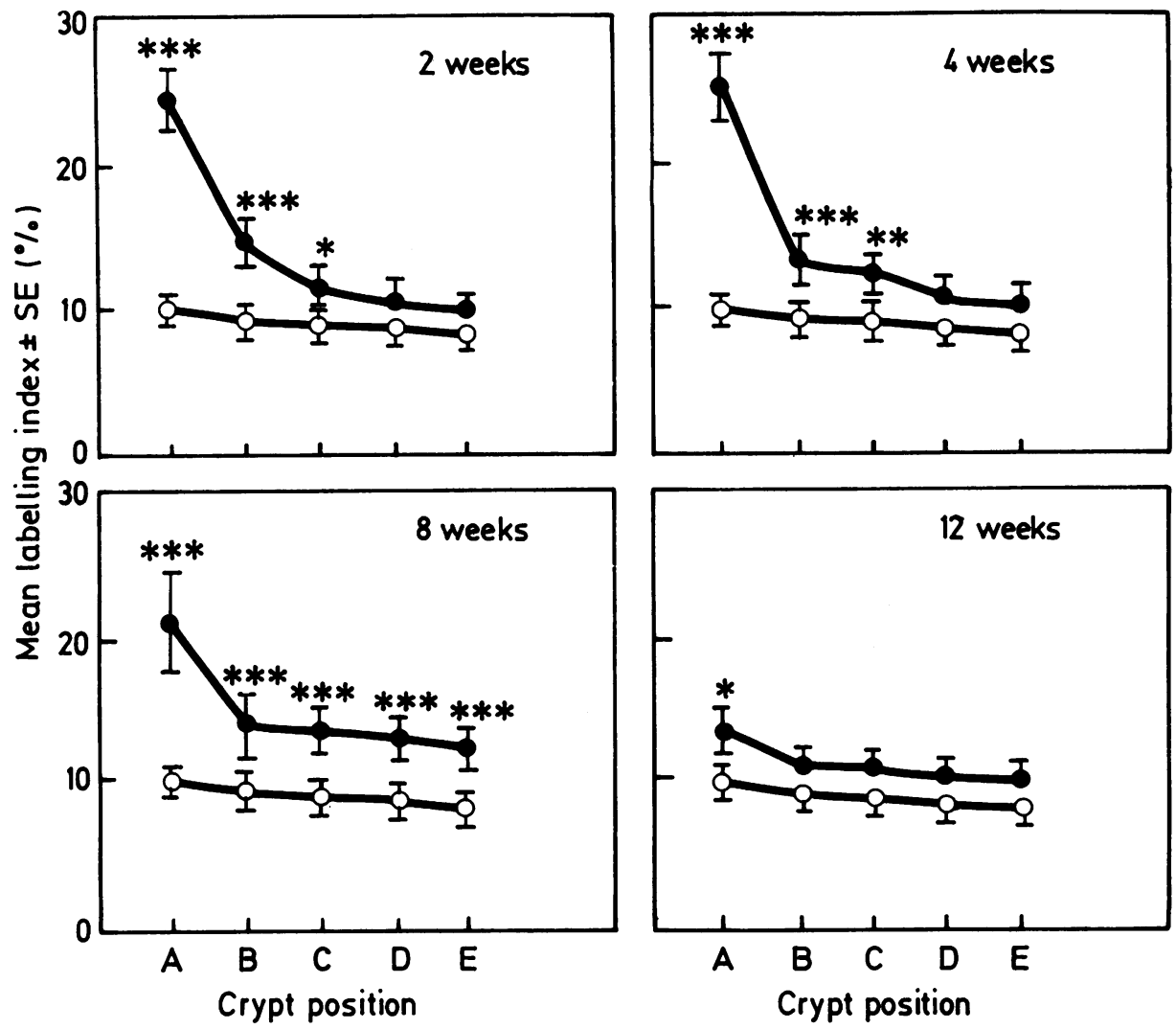

Fig. 8 Crypt labelling index in unoperated control rats $\left(\mathrm{O}_{-} \mathrm{O}\right)$ and rats receiving transection $\left(\mathrm{O}_{-}\right)$with time $\left({ }^{* * *} p<0.001,{ }^{* *} p<0.02,{ }^{*} p<0.05\right)$.

The development of anastomotic tumours has been attributed to the continued presence of suture material, acting as a chronic irritant. A suture placed in the rat caecum leads to increased thymidine uptake by adjacent epithelial cells and promotes local carcinogenesis. ${ }^{13}$ In man, microscopic examination of anastomotic recurrence showed intramucosal fibrosis, non-specific chronic inflammation and a foreign body granulomatous reaction to suture material in addition to the focus of adenocarcinoma.$^{14}$ Despite using a non-absorbable suture material (silk), we seldom observed a chronic inflammatory response on the mucosal aspect of the healed anastomosis. More often we saw foreign body granulomatous reaction in the adventitia in response to the marker stitch placed on the serosal aspect of the colon. Furthermore the incidence of suture line cancer in rats is not affected by using absorbable or non-absorbable sutures. ${ }^{15} 16$

A more plausible explanation for the development of anastomotic tumours in our experimental system is the selective action of azoxymethane on rapidly dividing crypt cells. In support, crypts in the immediate vicinity of the anastomosis retain a higher proliferative activity even after returning to a normal histological appearance. Stimulated crypt cell proliferation near the site of an anastomosis has been reported after transection of both small bowel ${ }^{17}$ and transverse colon. ${ }^{18}$ Whereas Barkla and Tutton detected an increase in colonic crypt cell proliferation at four weeks only, we have found that the response persists for three months (although diminishing progressively). Stem cells are believed to be the target for the transforming effect of carcinogens, ${ }^{1920}$ and these are presumably present in greater numbers during the spurt of proliferative activity that accompanies anastomotic healing.

The clinical implications of these findings are unclear. Clearly reparative hyperplasia is necessary to ensure safe healing of the anastomosis and should not be disturbed. Other situations in which increased cell proliferation potentiates carcinogenesis include chronic ulcerative proctocolitis, ${ }^{21-23}$ ureterosigmoidostomy undertaken for benign or malignant 
disease $^{24}$ and possibly pelvic irradiation. ${ }^{625}$ The hyperplastic response to different types of injury may therefore be sufficient to trigger malignant change in susceptible individuals.

We wish to thank Mr P W Davies for assistance with animal operations and Drs Stephen Kelly and Susan Evans for their help with the statistical analysis of data. This work was supported by a grant from the Cancer Research Campaign, which we gratefully acknowledge.

\section{References}

1 Welch JP, Donaldson GA. The clinical correlation of an autopsy study of recurrent colorectal cancer. Ann Surg 1979; 189: 496-502.

2 Enker WE, Dragacevic S. Multiple carcinomas of the large bowel: a natural experiment in aetiology and pathogenesis. Ann Surg 1978; 187: 8-11.

3 Hickey RCN, Romsdah MM, Johnson DE, et al. Recurrent cancer and metastases. World J Surg 1982; 6: 585-95.

4 Anderson JM. Chemotherapeutic prevention of local recurrence after stapled anastomosis in rectal cancer. Scott Med J 1981; 26: 21-33.

5 Umpleby HC, Fermor B, Symes MO, Williamson RCN. Viability of exfoliated carcinoma cells. Br J Surg 1984; 71: 659-63.

6 Umpleby HC, Bristol JB, Rainey JB, Williamson RCN. Survival of 727 patients with single carcinomas of the large bowel. Dis Colon Rectum 1984; 27 : 803-9.

7 Williamson RCN, Davies PW, Bristol JB, Wells M. Intestinal adaptation and experimental carcinogenesis after partial colectomy. Increased tumour yields are confined to the anastomosis. Gut 1982; 23: 316-25.

8 Harte PJ, Steele G, Rayner AA, Munroe AE, King VP, Wilson RE. Effect of major small bowel resection on dimethylhydrazine-induced bowel carcinogenesis. J Surg Oncol 1981; 18: 87-93.

9 Aldewachi HS, Wright NA, Appleton DR, Watson AJ. The cell cycle time in the rat jejunal mucosa. Cell Tiss Kinet 1974; 7: 587-94.

10 Williamson RCN, Bauer FLR, Ross JS, Oscarson JEA, Malt RA. Promotion of azoxymethane-induced colonic neoplasia by resection of the proximal small bowel. Cancer Res 1978; 38: 3212-17.

11 Williamson RCN, Bauer FL, Ross JS, Watkins JB, Malt RA. Enhanced colonic carcinogenesis with azoxy- methane in rats after pancreaticobiliary diversion to mid small bowel. Gastroenterology 1979; 76: 1386-92.

12 Druckrey H, Lange A. Carcinogenicity of azoxymethane dependent on age in BD rats. Fed Proc Fed Am Soc Exp Biol 1972; 31: 1482-4.

13 Pozharisski KM. The significance of nonspecific injury for colon carcinogenesis in rats. Cancer Res 1975; 35: 3824-30.

14 Ross JS. Experimental large intestinal adenocarcinoma induced by hydrazines and human colorectal cancer: a comparative study. In: Malt RA, Williamson RCN, eds. Colonic carcinogenesis. Lancaster: MTP, 1982: 187-209.

15 Byrne PJ, Stephens RB, Hennessy TPJ, West AB, Sheahan DG. Colon cancer at sites of anastomosis. Lancet 1984; i: 225.

16 Calderisi RN, Freeman HJ. Differential effects of surgical suture materials in 1-2-dimethylhydrazineinduced rat intestinal neoplasia. Cancer Res 1984; 44: 2827-30.

17 Sharp JG, Hanson WR, Osborne JW. The relationship between the compensatory response in the stomach and colon and the extent of small bowel resection in the rat. Virchows Arch [Cell Pathol] 1983; 44: 295-304.

18 Barkla DH, Tutton PM. The influence of surgical transection and anastomosis on the rate of cell proliferation in the colonic epithelium of normal and DMHtreated rats. Carcinogenesis 1983; 4: 1323-25.

19 Chang WL. Pathogenesis and biological behaviour of 1-2 dimethylhydrazine-induced colonic neoplasms in the mouse. In: Appleton DR, Sunter JP, Watson AJ, eds. Cell proliferation in the gastrointestinal tract. Tunbridge Wells: Pitman Medical, 1980: 278-97.

20 Bykorez AJ, Ivashchenko YD. Gastrointestinal stem cells and their role in carcinogenesis. Int Rev Cytol 1984; 90: 309-73.

21 Allan A, Bristol JB, Williamson RCN. Crypt cell production rate in ulcerative proctocolitis: differential increments in remission and relapse. Gut 1985; 26: 999-1003.

22 Chester JF, Gaissert HA, Ross JS, Malt RA, Weitzman SA. Augmentation of 1,2-Dimethylhydrazine-induced colon cancer by experimental colitis in mice: role of dietary vitamin E. J N C I 1986; 76: 939-42.

23 Maratka Z, Nedbal J, Kocianova J, Havelka J, Kudrmann J, Hendl J. Incidence of colorectal cancer in proctocolitis: a retrospective study of 959 cases over 40 years. Gut 1985; 26: 43-9.

24 Stewart M. Urinary diversion and bowel cancer. Ann $R$ Coll Surg Engl 1986; 68: 98-102.

25 Sandler RS, Sandler DP. Radiation-induced cancers of the colon and rectum: Assessing the risk. Gastroenterology $1983 ; 84: 51-7$. 